\title{
AC 2008-1926: ALIGNING STUDENT LEARNING, FACULTY DEVELOPMENT AND ENGINEERING CONTENT: A FRAMEWORK FOR STRATEGIC PLANNING OF ENGINEERING INSTRUCTION AND ASSESSMENT
}

\section{Arunkumar Pennathur, University of Texas-EI Paso}

Arunkumar Pennthur is Associate Professor of Industrial Engineering at UTEP. He teaches work design, senior design and human factors engineering. His research interests are in virtual collaboration and problem representation in engineering education.

\section{Louis Everett, University of Texas-El Paso}

Louis Everett is Professor and Chair of Mechanical Engineering at University of Texas at El Paso. He teaches Dynamics and Controls. His research interests are in metacognition in engineering education. 


\title{
Aligning Student Learning, Faculty Development and Engineering Content: A Framework for Strategic Planning of Engineering Instruction and Assessment
}

\begin{abstract}
This paper outlines an innovative framework for modeling and planning engineering education assessment interventions. The theoretical bases for the framework are primarily derived and integrated from research methods and findings in several different disciplines - human engineering, engineering education, human communication sciences and, mathematical modeling using statistical and neural network approaches. The framework consists of four key elements - the task of instruction, the players including students, faculty, and other stake-holders such as employers, the tools used in the learning enterprise including traditional and modern technology tools, and the environment for learning. Using the framework presented, variables associated with the task, the players, the tools, and the environment can be visualized and analyzed in 3-dimensional space using multidimensional scaling and neural network methods. One aspect of the framework, reflections from an engineering faculty member, is analyzed to demonstrate how strategic planning can be facilitated through assessment and analysis with the framework.
\end{abstract}

\section{Model for strategic assessment planning}

Adapted from the Task, Operator, Machine, Environment (TOME) framework from the human factors engineering discipline ${ }^{1}$, the main elements of the proposed model for assessment of engineering education (figure 1) are:

(1) the task of instruction: The purpose of the proposed model is to design the task of instruction for achieving the desired outcome of learning and development. All other model elements are intended to study and design the task of instruction. Therefore, the task element is a superset of all other model elements and is not represented in figure 1. At a more detailed level of modeling and analysis, task-related variables such as task sequencing (precedencerelationships among instructional tasks for example), task frequency (how often should an instructor use a certain tool for instruction), task duration (how long should an instructor teach a certain piece of instruction), task criticality (how critical is one task for success of the entire instructional piece), task discretion (e.g., what amount of discretion does the instructor have in using a certain instructional technique), and task content (what is the content of instruction), are some of the key task-related factors that need consideration. Of particular importance is task content, because the goal of formally designing the instructional task is to narrow the distance between the learners and the task content. Hence, content is explicitly included in our model. We consider all other task-related variables as part of a large strategy pool to optimize the distances between the content and the learners.

(2) the players in the task: The main players with significant roles in the proposed model are the students, the faculty, and employers of students. Because student learning is primarily modeled, students are stakeholders; because faculty deliver instruction and facilitate student learning, they play a role in the model; and engineering employers influence the model by 
helping define requirements for engineering content included in the model. Additionally, employers indirectly influence the model elements by hiring students who learn and graduate from the system. Other players include for example administrators and funding sponsors who can also be included in extensions of this basic framework. Just as with detailed task-related variables, at a more detailed level of modeling, typical stakeholder related variables could include extent of prior knowledge, industrial experience, relevant skills possessed, learning styles, personality traits, age, gender, attitudinal and motivational factors, and socio cultural factors.

(3) the tools used in the task: The tools used for performing the task of instruction could be technological tools such as CAD software, a WebCT discussion forum, or a video podcast delivered on an iPod, or the more traditional chalkboard.
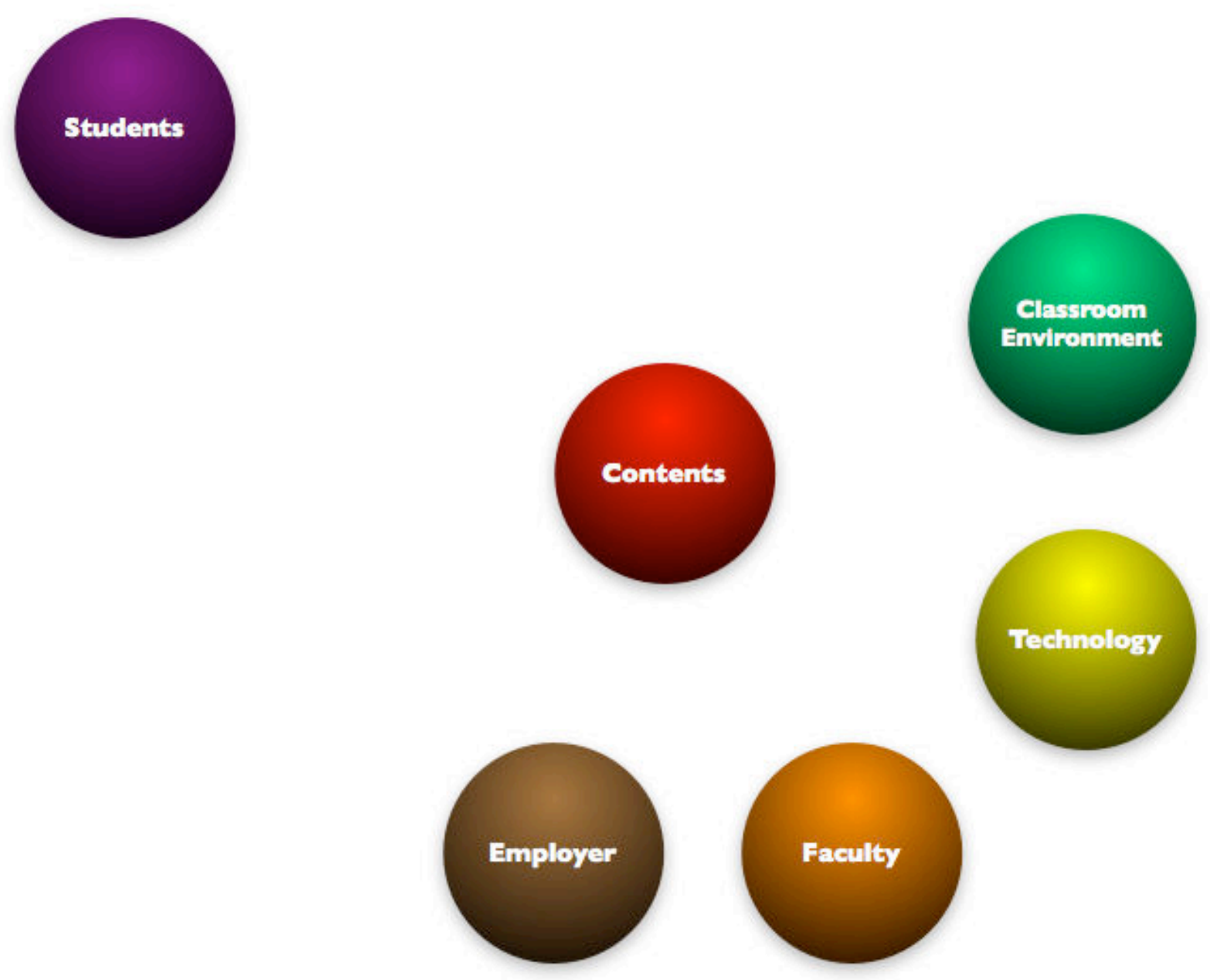

Figure 1. Model for Strategic Engineering Assessment Planning (State Space 1) 


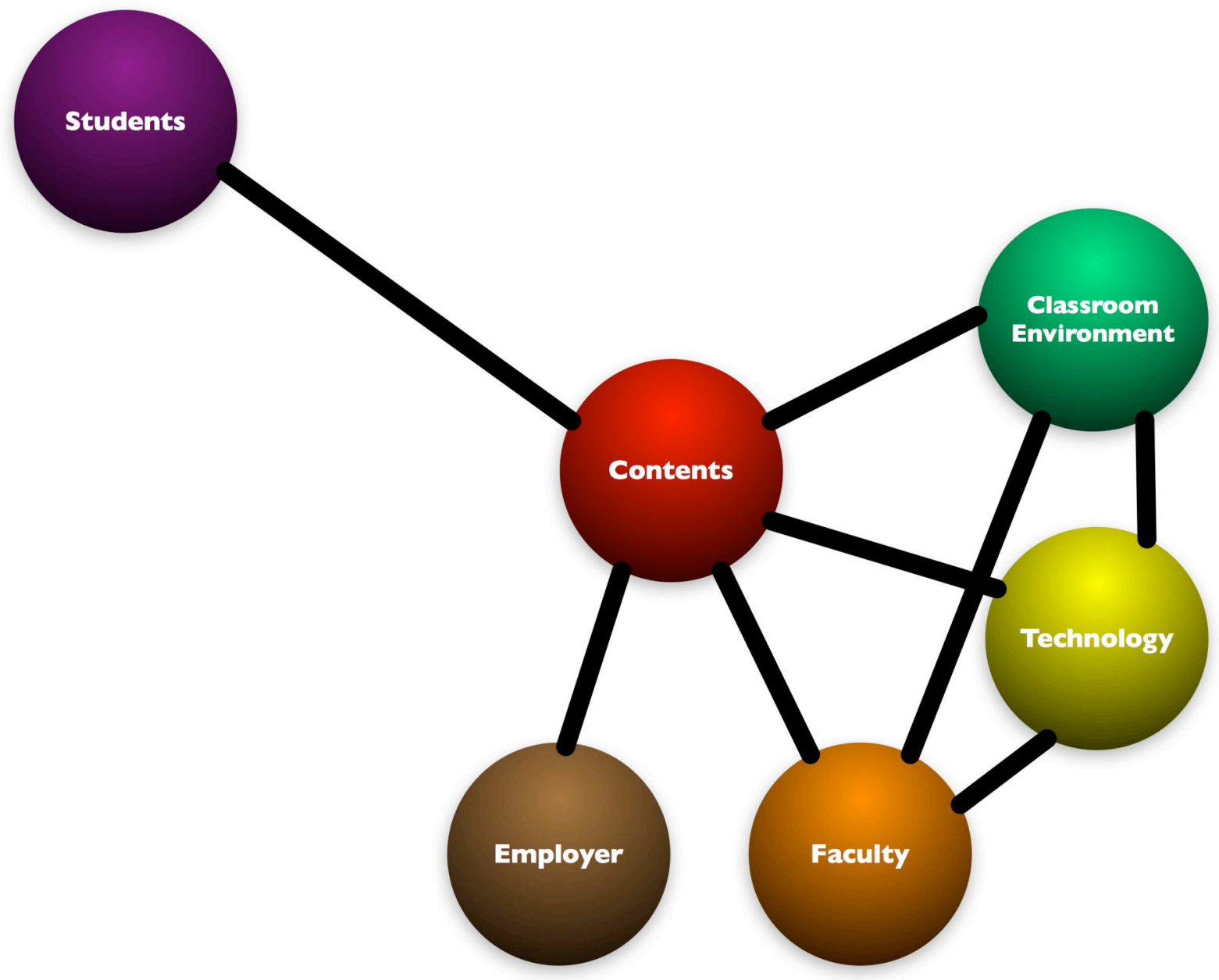

Figure 2. Model elements indicating links and distances between elements (State Space 2)

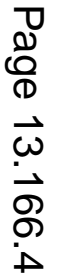




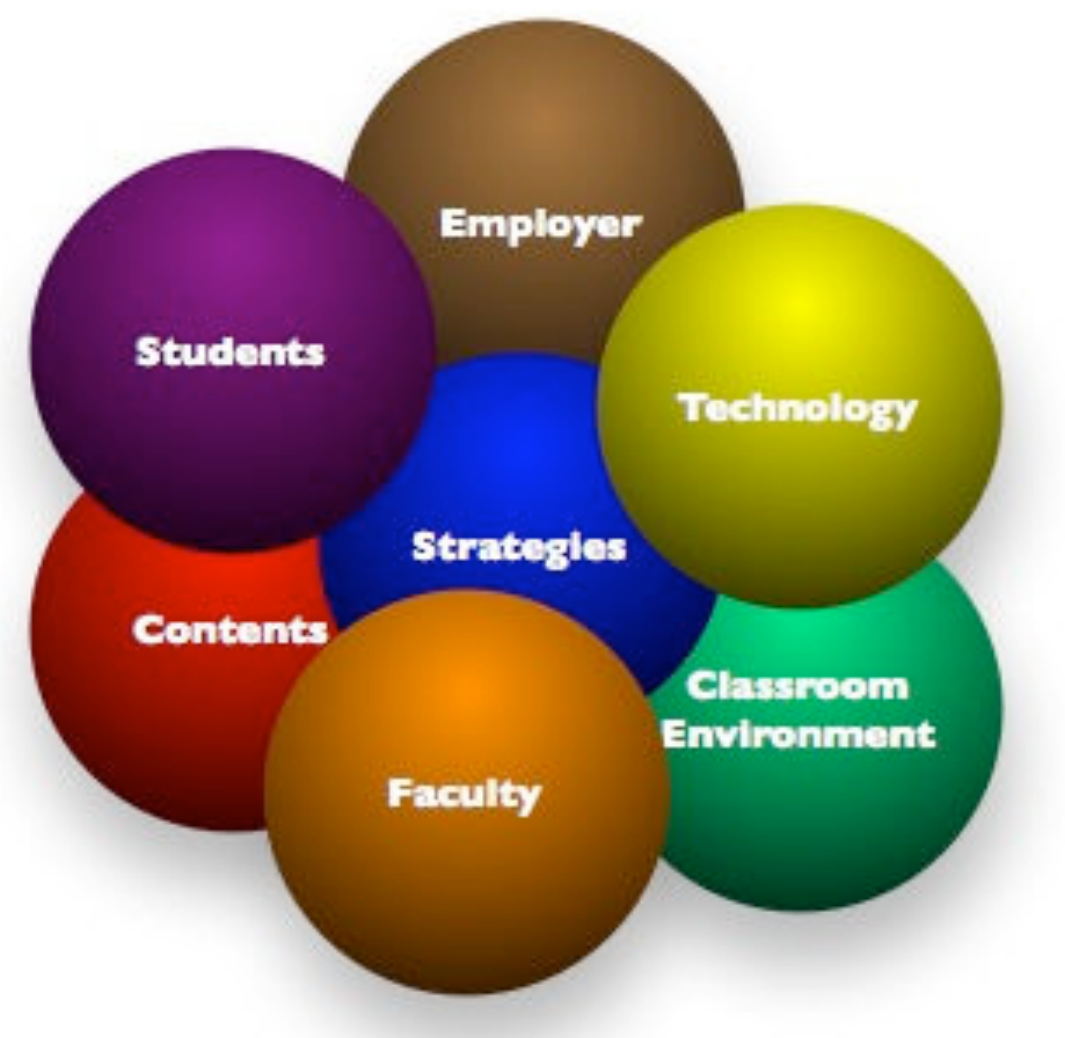

Figure 3. Strategies bind all model elements at small inter-elemental distances (State Space 3)

(4) the environment: The environment in the model includes primarily the learning environment created for instruction. For simplification, the classroom environment is included in the model in figure 1 but could easily be extended to environments outside the classroom as well. Environmental factors could include physical environment (for example, the physical location and arrangement of the furniture in the classroom), and policy related variables (such as attendance policy, grading policy, etc.).

\section{Use of the model framework}

Figures 1, 2 and 3 collectively illustrate how the proposed model framework can be used for modeling strategic planning activities for engineering education assessment. In figure 1, elements described in section 1 can be thought to exist without any connections or weak interconnections. Figure 1 could be considered as representing a state space 1 , representing initial state of the strategic planning model. Figure 2 represents the same elements in the framework but with connections represented by lines. This is a different state space 2 than state space 1. Using modeling concepts from multidimensional scaling theory ${ }^{2,3,4,5}$, these connections can be thought of as distances in space between the elements.

In transitioning from state space 1 to state space 2 , links or connections with certain strength of 
connections (can represented visually by the thickness of the lines) between elements are established. In addition, distances between the elements are established. For example, in figure 2, there is a connection between students and content; also, students and content are at a certain distance from each other. Similarly, faculty and technology elements have a connection, and faculty and classroom environment have a connection. As represented in figure 2, the facultytechnology link may be smaller in distance than the faculty-classroom environment link in an instance as the faculty member may be very proficient in the use of the technology or the tool, but may be poor at creating a classroom environment that can promote learning. It can also be noted from figure 2 that it is possible to have one-to-one, one-to-many and many-to-one mappings between the elements. Thus, while students and content have a one-to-one mapping in figure 2, content has a one-to-many mapping, and a many-to-one mapping with all other elements.

Figure 3 can be thought of as the final desired state space 3. In moving from state space 2 to state space 3, the distances between elements have been narrowed in this illustration. Strategies are at the core of the state space 3, and bind and hold the elements together. Another interpretation of strategies is that it is composed of parts of all elements, and are employed along the line segments in the connections between elements in state space 2, to move the elements closer together or to move certain elements farther apart based on what is desired.

The desirability of any state space configuration can be determined by learning outcome measures. Hence, if a certain state space results in maximizing learning gains or other measures of performance, then the strategic plan for instruction and assessment can be considered optimal.

To summarize, state spaces provide a snapshot of the instruction and assessment plan at any point in time. State spaces evolve and progress toward a desired state space. The progression toward a desired state space is achieved through strategies generated to position the elements in the state space. Thus, strategies may be employed to reduce or increase distances between elements, thus changing their positions in the state space. If expert strategies are available for modeling any of the connections in any state space, the elements at the end of these connections can be fixed in space.

There can be several other potential uses for the model. For the same engineering content, different engineering faculty may employ different strategies, and hence obtain different intermediate and final state spaces. Hence the model can serve as a visual tool and platform for facilitating shared understanding of faculty strategies. Further, as illustrated in the short example in section 3 on one aspect of the framework, the model is not merely visual in nature. It has mathematical sophistication and rigor based on multidimensional scaling theory.

\section{Illustrative example}

The example described here is from an Industrial Engineering junior level course in Systems Engineering. It should be noted that the example described in this section is only one small aspect of planning that can be accomplished with the framework and model. The course was part of an NSF Phase 2 CCLI Grant to investigate use of metacognition and inquiry-based methods for cultivating the authentic 2020 engineer. As part of the effort to metacognize, the engineering 
faculty member teaching the course wrote reflections for every class period taught. The reflections were in the form of written text describing plans for a class session, and describing, after class, how the class went.

A product design project was a major component of the systems engineering course. Students worked in teams on a sequential design process for designing a consumer product. They collected customer requirements, translated customer requirements into technical specifications, generated several alternative concepts (in the form of sketches) based on the specifications, and using engineering criteria, selected promising concepts for further development. Students also presented their proposal ideas, presented a mid-term update, and presented their entire project effort in a final presentation. This course addressed ABET outcomes c (ability to obtain client requirements, and design a system, component, or process related to IE to meet client requirements), $d$ (ability to function as a team member in team-based problem solving activities), and $\mathrm{g}$ (ability to communicate effectively in written and verbal forms).

To cultivate the desired abilities in students (the learning outcomes $\mathrm{c}$, d, and g), and to enable them to succeed in their design project, the faculty member teaching the course included several focused in-class activities and example scenarios intended to simulate steps in the product design process. These included activities on teamwork, activities for customer needs identification, activities to translate customer requirements, activities to replicate concept generation and concept selection. Additionally, at the end of every in-class activity, student teams reported out their process and their product. Questioning, reflective thinking, and verbalization ${ }^{6}$ of feedback were used to probe student understanding of the concepts in each step in the product design process.

For the engineering faculty teaching the course, to plan, implement and manage all these class activities required reflection and thinking at both the strategic and the tactical levels. For example, at the strategic level, designing the sequence of classroom activities had to be planned. Managing and steering the classroom discussion required tactical thinking. Written reflections from the faculty member were intended to capture this thinking. Although writing reflections on planning and implementation can be viewed as burdensome, documenting reflective practice with help of technologies such as a blog, for example, can not only help faculty write about their planning in the form of reflections, but there may be other additional benefits in blogging their reflection. If students know what faculty do to prepare for their classes, and how they prepare and plan for their classes, students will appreciate the effort of faculty more, resulting in useful adjustments to alignment between faculty planning and student learning.

It is easy to see how the example would fit the model framework. Some model elements in the example include the faculty member, the students, the content, the classroom environment and its planning, and use of WebCT discussion forums for student collaborative activity for the project. The primary concern of the faculty member was to reduce the distance between the students and the content (employer-driven), while at the same time, having the students become active, selfguided learners. The goal for the faculty member was to try to move away from a lecture-based model of instruction to an active classroom where students did most of the talking and doing. The goal for the instructor was to merely act as a sounding board and a scaffold for the students. 


\subsection{Analysis methods}

Written text documents containing reflections of the faculty member from the class sessions in August, September and October were analyzed using a self-organizing artificial neural network computer program for text analysis called Catpac ${ }^{7}$. The neural network in Catpac identifies the most frequently occurring words in a text, and determines similarity patterns based on cooccurence of words. Each major word in the text (after elimination of appropriate stop words such as articles, prepositions, conjunctions, etc.) is assigned a neuron. A scan window is then run through the text. Neurons associated with specific words are activated when encountering these words and are active as long as the word remains in the scan window. The idea is that classical conditioning just like in the human brain, will strengthen the connections between simultaneously active neurons. The pattern of weights (based on similarities matrix) provides complete information about similarities among all words in the text and permits meaningful conceptual groupings of words (in the form of dendrograms and perceptual maps) generated by cluster analyses methods and multidimensional scaling of the co-occurence matrices.

\subsection{Results and summary}

For illustration purposes and for reasons of brevity, only results from analysis of the August and October faculty reflections are presented in this paper. Table 1 presents results from the text analysis of August and October (data in parenthesis) reflections respectively. Two significant findings from table 1 are related to the total number of words, and the use of the word " $P$ ' in the reflections. The total number of words written in the reflections increased significantly from August to October 2006, indicating in general that the faculty member wrote more in the reflections (possibly an influence of thinking more and having more planning issues to think about). Additionally, the word $I$ was used almost twice as more (a 5\% increase) in October than in August. This could be an indication that the faculty member was being reflective at an increasing rate about the role he played in designing the class interventions. The use of the word team is also significantly higher in October than in August.

TABLE 1. Frequency of words in reflections.

\begin{tabular}{|l|l|l|}
\hline Word & Freq. (October) & $\begin{array}{l}\text { Percentage (Total 679 } \\
\text { words in Aug \& 1156 in } \\
\text { Oct) }\end{array}$ \\
\hline I & $95(229)$ & $14(19.8)$ \\
\hline Team & $55(71)$ & $8.1(6.1)$ \\
\hline Class & $42(47)$ & $6.2(4.1)$ \\
\hline Teams & $35(24)$ & $5.2(2.1)$ \\
\hline Students & $27(17)$ & $4.0(1.5)$ \\
\hline Project & 26 & 3.8 \\
\hline Think & $21(32)$ & $3.1(2.8)$ \\
\hline Ideas & 16 & 2.9 \\
\hline Process & 19 & 2.8 \\
\hline
\end{tabular}


Figures 4 and 5 illustrate the perceptual maps generated based on multidimensional scaling for August and October respectively. It can be seen from the perceptual maps that the word "I" in the October map is at a greater distance from the other clusters of words than the " $I$ " in the August map. This is an indication that the faculty member was acting more as a facilitator for class activities in October compared to August, when class mechanics and processes were still being established between the faculty member and the students. Other interpretations based on the clusters in the map (and the distance matrices) and longitudinal data from other classes are being similarly established. With increased emphasis among researchers on the science of learning, the framework outlined offers a multidimensional approach for viewing the engineering instruction and assessment functions in the educational enterprise.

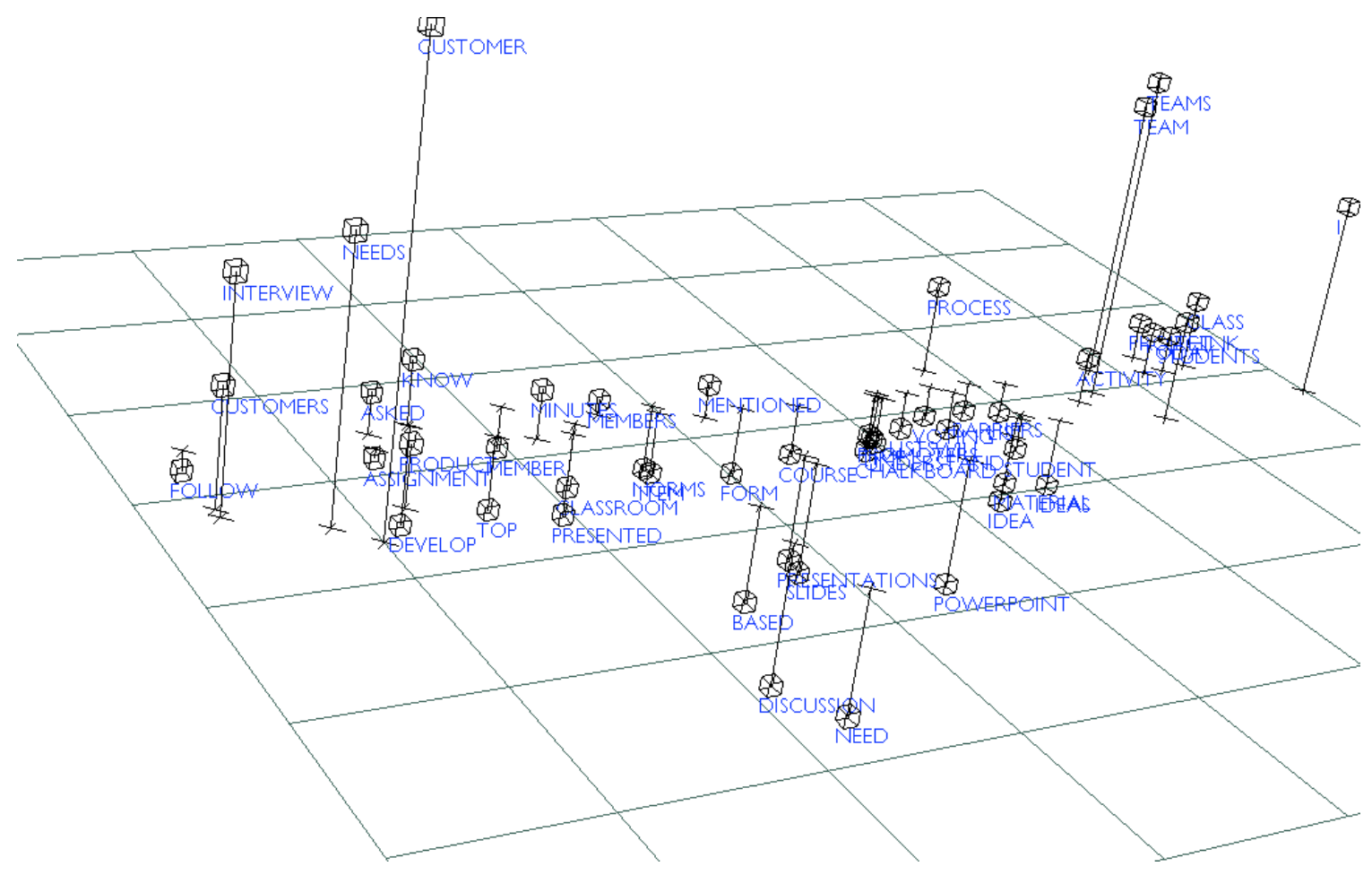

Figure 4. Perceptual map indicating word clusters from August reflections 


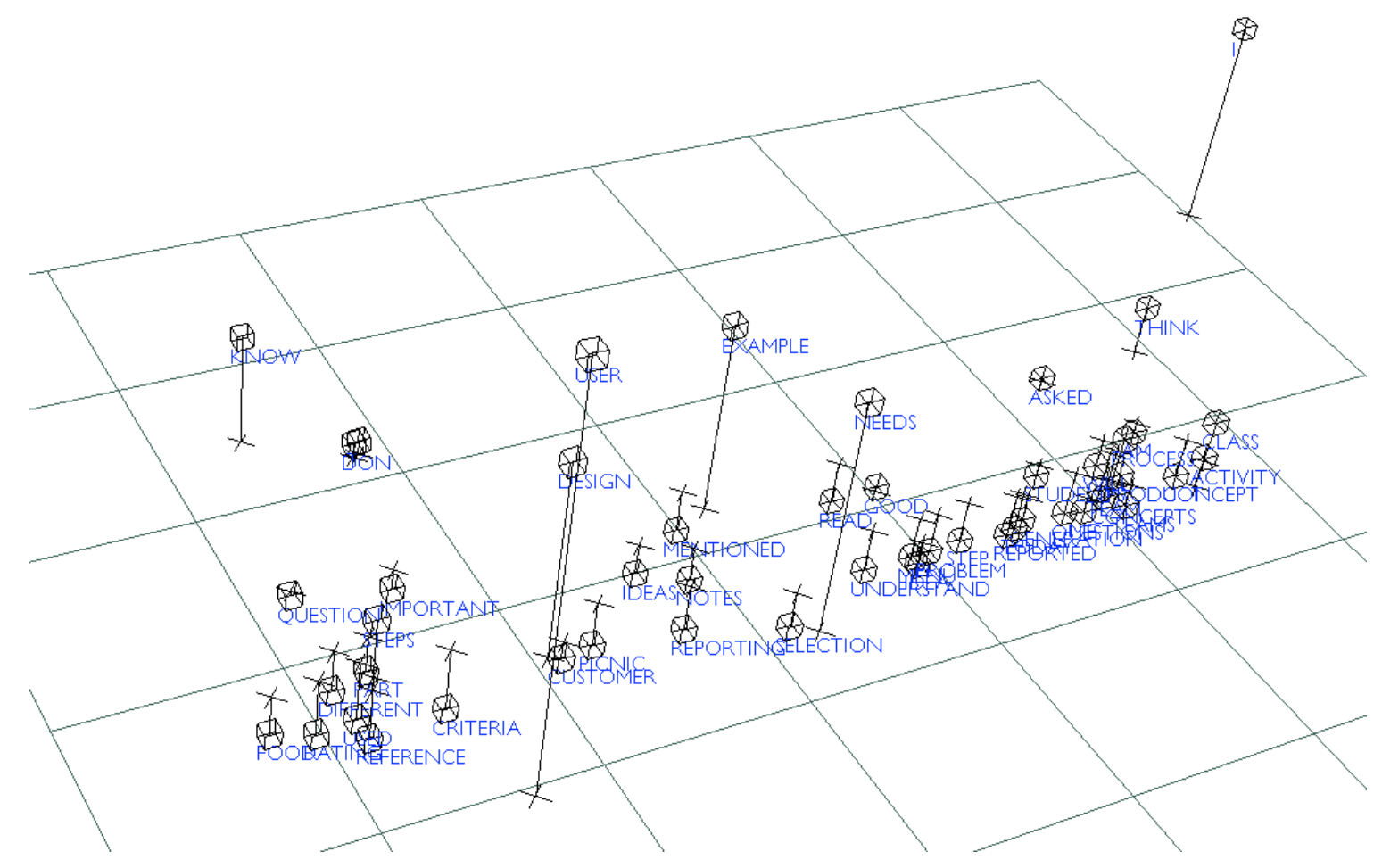

Figure 5. Perceptual map indicating word clusters from October reflections

\section{Acknowledgment}

Support for this research is provided by NSF-CCLI Award Number 0618861.

\section{Bibliography}

[1] A. Mital, A. Pennathur. Perspectives on Designing Human Interfaces for Automated Systems. In R. L. Shell \& E.L. Hall (Eds.) Handbook of Industrial Automation, New York, NY: Marcel Dekker, Inc., 2000.

[2] I. Borg, P. Gronen. Modern Multidimensional Scaling: Theory and Applications. New York, NY: Springer-Verlag, 1997.

[3] M.F. Cox, M.A.A. Cox. Multidimensional Scaling, New York, NY: Chapman and Hall, 2001.

[4] H. Abdi. Metric Multidimensional Scaling. In N.J. Salkind (Ed). Encyclopedia of Measurement and Statistics, Thousand Oaks, CA: Sage Publications, 2007.

[5] W.S. Torgerson. Theory \& Methods of Scaling, New York, NY: Wiley Publications, 1958.

[6] J. Bransford. National Research Council (U.S.) Committee on Developments in the Science of Learning \& National Research Council (U.S.) Committee on Learning Research and Educational Practice. How People Learn: Brain, Mind, Experience, and School (Expanded Edition). National Academy Press, Washington, D.C., 2000. 
[7] J. K. Woelfel. User's Guide: Catpac II, Rah Press, 1998.

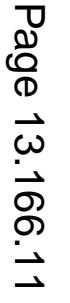

